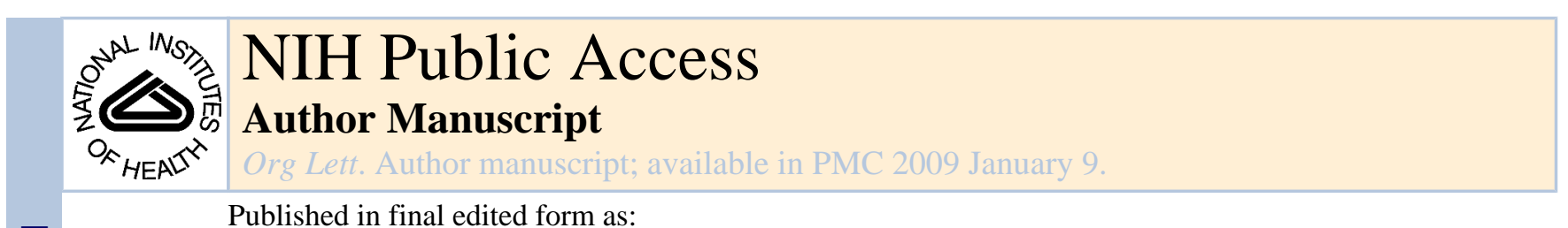

Published in final edited form as:

Org Lett. 2006 August 31; 8(18): 3987-3990. doi:10.1021/o1061439k.

\title{
De Novo Asymmetric Synthesis of Milbemycin $\beta_{3}$ via an Iterative Asymmetric Hydration Approach
}

\author{
Miaosheng Li and George A. O'Doherty \\ Department of Chemistry, West Virginia University, Morgantown, WV 26506
}

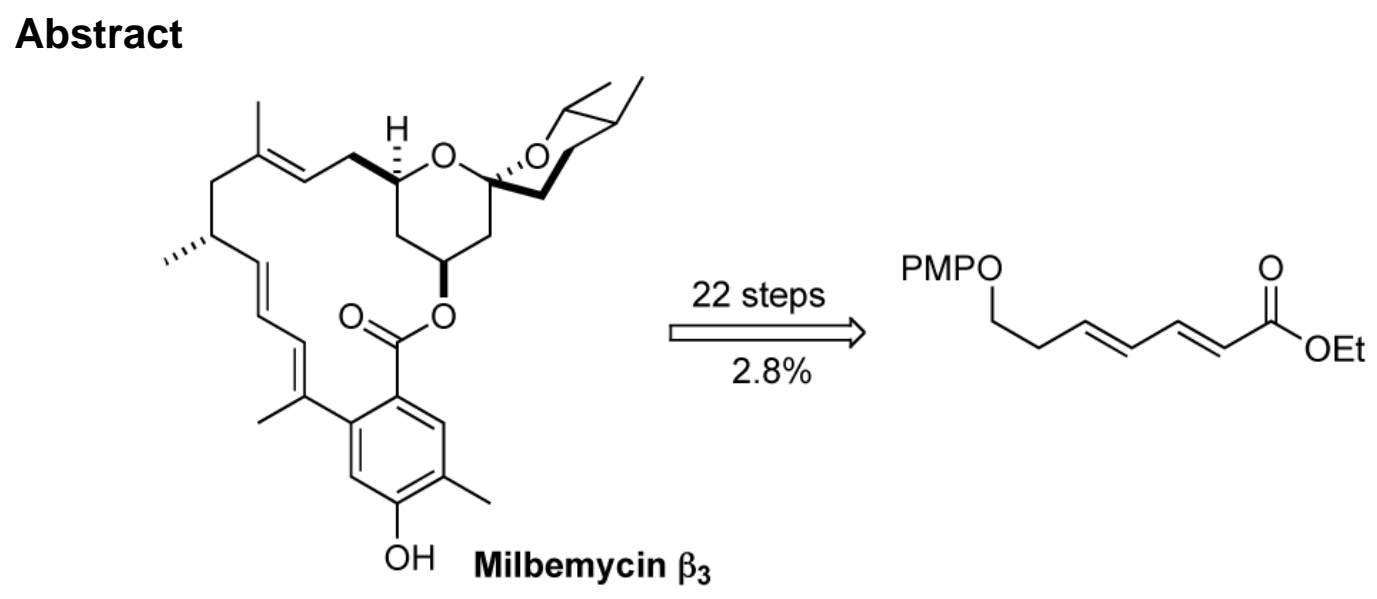

The enantioselective synthesis of the spiroketal/macrolide natural product milbemycin $\beta_{3}$ has been achieved in 22 steps and $2.8 \%$ overall yield from an achiral dienoate. The spiroketal ring system was installed by three sequential asymmetric hydrations followed by sprioketalization. Both the absolute and relative stereochemistry of milbemycin $\beta_{3}$ was introduced by two Sharpless asymmetric dihydroxylations, two $\pi$-allyl-palladium catalyzed reductions and an iridium catalyzed hydrogen migration/Claisen rearrangement to install the $C$-12 stereocenter.

Since their initial isolation and structural determination, the milbemycins ${ }^{1,2}$ have attracted significant interest for their potential use as pesticides and pharmaceuticals. In addition to antibiotic activity, various members of this class of spiroketal/macrolide natural products have shown significant activity against various agricultural pests (e.g. mites, beetles, and tent caterpillars) ${ }^{2,3}$ and parasites (e.g. nematodes, mites, ticks, and larvae of biting flies), 2,4 while displaying minimal cytotoxicity to plants and animals. 5 Pharmacological interest in the milbemycins re-emerged, after it was discovered that they are also potent efflux pump inhibitors. 6

In addition to this array of fascinating biological activities, the milbemycin structural complexity has also attracted the attention of the synthetic community. ${ }^{7,8}$ To date several total syntheses of milbemycin $\beta_{3}$ have been completed, ${ }^{7}$ along with various efforts to the spiroketal ring system. ${ }^{8}$ While all of the previous syntheses of the milbemycin (1) derived their asymmetry from the chiral pool, we were interested in a de novo asymmetric approach that would use asymmetric catalysis to install the six stereocenters in milbemycin $\beta_{3}$ from achiral

George.ODoherty@mail.wvu.edu.

Supporting Information Available: Complete experimental procedures and spectral data for all new compounds can be found in the Supporting Information. This material is available free of charge via the Internet at http://pubs.acs.org. 
starting materials (5 and 10, Scheme 1). ${ }^{9}$ Herein we describe our successful efforts to implement this strategy for the de novo synthesis of milbemycin $\beta_{3}$.

Retrosynthetically, we envisioned milbemycin $\beta_{3}(\mathbf{1})$ being prepared by an olefination/ macrolactonization strategy. This transform divided the molecule into two halves, an achiral phosphine oxide 3, which was first prepared by Smith, ${ }^{10}$ and a silyl-protected hydroxyaldehyde 2 , which possessed both the spiroketal and the five chiral centers of milbemycin. Following the Barrett precedent, we planned to install the sixth chiral center during a Mitsunobu macrocyclization. ${ }^{11}$

Using a transition metal variant of the Smith's vinyl anion addition Claisen rearrangement, we planned to prepare 2 from spiroketal $\mathbf{4}$, which in turn could be prepared from the partially protected tetraol $\mathbf{6}$. Finally, we hoped to establish the four chiral centers and triol functionality of 6 by the iterative use of our asymmetric hydration protocol (i.e. 10 to 8 and 7 to 6 ). ${ }^{12}$

In practice dienoate $\mathbf{1 0}$ was prepared by a 3-step protocol from commercially available $\mathbf{1 1}$ via protection, carboxylation and ynoate isomerization. ${ }^{13}$ Using our 3 -step asymmetric hydration protocol (dihydroxylation, carbonate formation and palladium catalyzed reduction) ${ }^{12}$ dienoate 10 was regio- and enantioselectively transformed into $\delta$-hydroxy enoate $\mathbf{1 4}$, which in turn was diastereoselectively hydrated to form the protected 3,5-dihydroxy ester 15 using Evans' procedure. ${ }^{14}$ The ester 15 was then converted into the $\beta$-keto-phosphonate 8 via Weinreb amide 16 ( $75 \%$ for the two steps).

The last five carbons of the spiroketal portion of milbemycin $\beta_{3}$ came from angelaldehyde (9) and were installed via a Horner-Wadsworth-Emmons reaction with 8. Exposure of ketophosphonate 8 to aldehyde 9 with $\mathrm{Cs}_{2} \mathrm{CO}_{3}$ as base produced the $E$,Z-dienone 7 in $82 \%$ yield (Scheme 4). Using a similar 3-step sequence, as on dienoate 10, dienone 7 was diastereoselectively hydrated (7 to 17a). ${ }^{12}$ Regioselective dihydroxylation of 7 gave an inseparable diols $\mathbf{1 7} \mathbf{a} / \mathbf{b}$ in $58 \%$ yield and diastereocontrol. ${ }^{15}$ Because of the distance between the relevant stereocenters, it was difficult to distinguish diastereomers $17 \mathbf{a}$ and $17 \mathbf{b}$ by ${ }^{1} \mathrm{H}$ NMR and TLC. Thus, Mosher ester analysis (17a/b to $\mathbf{1 8 a} / \mathbf{b}$, see Supporting Information) was used to determine the diastereomeric ratio of $\mathbf{1 7} \mathbf{a}$ to $\mathbf{1 7} \mathbf{b}(\mathrm{dr}=11: 1)$. The mixture of diastereomers $\mathbf{1 7} \mathbf{a} / \mathbf{b}$ was converted into cyclic carbonates and stereoselectively reduced with $\mathrm{HCO}_{2} \mathrm{H}_{/} / \mathrm{Et}_{3} \mathrm{~N}$ and catalytic palladium(0) in $\mathrm{CH}_{2} \mathrm{Cl}_{2} /$ hexane to give alcohols $\mathbf{6 a} / \mathbf{b}(93 \%) .{ }^{16}$ As with $\mathbf{1 7 a} \mathbf{a} / \mathbf{b}$, the diastereomers $\mathbf{6 a} / \mathbf{b}$ were not easily differentiated by ${ }^{1} \mathrm{H}$ NMR or separated by chromatography. The diastereomeric alcohols $\mathbf{6 a} / \mathbf{b}$ were cleanly converted into spiroketal $\mathbf{1 9}$ via a one-pot hydrogenation/hydrogenolysis/spiroketalization procedure (92\%). The minor diastereomeric impurity in $\mathbf{1 9}$ was easily removed by recrystallization from a mixture of EtOAc/hexanes (9:1). The $C$-19 alcohol was protected as the TBDPS-ether, the PMP-group was oxidatively removed with CAN and the $C-15$ alcohol was oxidized to the aldehyde with the Dess-Martin reagent in an $83 \%$ overall yield.

We next looked to extend the $C-15$ aldehyde to the $C$-11 aldehyde. Based on the Smith synthesis, we planned to establish the $C$-14/C-15E-double bond and the $C$ - 12 stereocenter by a Claisen rearrangement. In contrast to Smith's use of an Ireland enolate rearrangement, we chose to use the isomerization-Claisen rearrangement (ICR) developed by Nelson. ${ }^{17}$ This procedure has the added advantage of providing the aldehyde $\mathbf{2}$ directly.

When aldehyde $\mathbf{4}$ was exposed to a vinylcuprate reagent an exceedingly diastereoselective addition ( $\mathrm{dr}>20: 1)$ occurred to give allylic alcohol 20 in good yield (78\%). The allylic alcohol $\mathbf{2 0}$ was allylated with KH/AllylBr to give allylic ether $\mathbf{2 1}$ in nearly quantitative yield (99\%). Following the Nelson protocol allylic ether $\mathbf{2 1}$ was exposed to catalytic iridium and tricyclohexyl phosphine. Under these conditions, allylic ether $\mathbf{2 1}$ cleanly rearranged to the $E$ enolether 22, at which point $6 \mathrm{~mol} \% \mathrm{PPh}_{3}$ was added and the dichloroethylene solution was 
refluxed. After heating for $24 \mathrm{~h}$ an $83 \%$ yield of aldehyde $\mathbf{2}$ was isolated. While aldehyde $\mathbf{2}$ can be purified by $\mathrm{SiO}_{2}$ chromatography, this leads to lower diastereoselectivity $(\mathrm{dr}=4: 1)$. The preferred procedure was to use the crude aldehyde in the subsequent transformation. Analysis of the crude ${ }^{1} \mathrm{H}$ NMR indicated that the diastereomeric ratio of crude 2 was on the order of 10:1.

Finally, with aldehyde $\mathbf{2}$ in hand, we set out to stitch the two fragments together via an olefination and lactonization. The $E, E$-diene of $\mathbf{2 3}$ was stereoselectively installed upon exposure of a crude solution of aldehyde 2 with the sodium salt of phosphine oxide $\mathbf{3}$. Before the lactonization could commence, the silyl-ether was removed (TBAF, 95\%) and the methyl ester was hydrolyzed ( $\mathrm{LiOH}, 78 \%$ ). Then following the Barrett procedure the 19-epi-seco acid 24 was lactonized with DIAD/PPh 3 in good yield (79\%). Using NaSEt the methyl protecting group was removed, providing $30 \mathrm{mg}$ of synthetic material that was physically (mp, optical rotation) ${ }^{18}$ and spectroscopically $\left({ }^{1} \mathrm{H}\right.$ NMR, ${ }^{13} \mathrm{C}$ NMR, IR and MS) identical to natural milbemycin $\beta_{3}(\mathbf{1})$.

In conclusion, a short de novo asymmetric synthesis of milbemycin $\beta_{3}(\mathbf{1})$ has been developed. This highly enantio- and diastereocontrolled route illustrates the utility of our dienoate/dienone asymmetric hydration strategy for natural product synthesis. In addition, it features the use of Nelson's isomerization-Claisen rearrangement (ICR) in a structurally complex setting. This approach provided milbemycin $\beta_{3}$ (1) in $2.3 \%$ overall yields from 5-hexyn-1-ol (11), which should be amenable to the preparation of its enantiomer. Further application of this approach to the synthesis of structurally more complex members of this class of compounds and biological testing is ongoing.

\section{Supplementary Material}

Refer to Web version on PubMed Central for supplementary material.

\section{Acknowledgment}

We are grateful to NIH (GM63150) and NSF (CHE-0415469) for the support of our research program and NSFEPSCoR (0314742) for a $600 \mathrm{MHz}$ NMR and an LTQ-FT Mass Spectrometer at WVU.

\section{References}

1. a Mishima H, Kurabayashi M, Tamura C, Sato S, Kuwano H, Saito A. Tetrahedron Lett 1975;16:711714. b Takiguchi Y, Ono M, Muramatsu S, Ide J, Mishima H, Terao M. J. Antibiot 1983;36:502-508. [PubMed: 6874568] c Takiguchi Y, Mishima H, Okuda M, Terao M, Aoki A, Fukuda R. J. Antibiot 1980;33:1120-1127. [PubMed: 7451362]

2. For a review see: a Shoop WL, Mrozik H, Fisher MH. Vet. Parasitol 1995;59:139-156. [PubMed: 7483237] b Aoki A. J. Pest. Sci 1992;19:245-247.

3. Thamsborg S, Roepstorff A, Larsen M. Vet. Parasitol 1999;84:169-186. [PubMed: 10456414]

4. Bowman DD, Parsons JC, Grieve RB, Hepler DI. Am. J. Vet. Res 1988;49:1986-1989. [PubMed: 3247924]

5. Material Safety Data Sheet: Moxidectin: Fort Dodge Animal Health. b Fisher MH. Pure Appl. Chem 1990;62:1231-1240.

6. Chamberland, S.; Lee, M.; Lomovskaya, O. Milbemycin class efflux pump inhibitors for treating microbial infections and cancer. 1999. WO 98-US20916 19981001AN1999:244572

7. a Smith AB III, Schow SR, Bloom JD, Thompson AS, Winzenberg KN. J. Am. Chem. Soc 1982;104:4015-4018. b Schow SR, Bloom JD, Thompson AS, Winzenberg KN, Smith AB III. J. Am. Chem. Soc 1986;108:2662-2674. c Williams DR, Barner BA, Nishitani K, Phillips JG. J. Am. Chem. Soc 1982;104:4708-4710. d Street SDA, Yeater C, Kocienski P, Campbell SF. J. Chem. Soc., Chem. Commun 1985:1386-1388. e Attwood SV, Barrett AGM, Carr RAE, Robinson G. J. Chem. Soc., 
Chem. Commun 1986:479-481. f Baker R, O'Mahony MJ, Swain CJ. J. Chem. Soc., Chem. Commun 1985:1326-1328. g Barrett AGM, Carr RAE, Attwood SV, Richardson G, Walshe NDA. J. Org. Chem 1986;51:4840-4856.

8. a Yeater C, Street SDA, Kocienski P, Campbell SF. J. Chem. Soc., Chem. Commun 1985:1388-1389. b Baker R, O'Mahony MJ, Swain CJ. Tetrahedron Lett 1986;27:3059-3062. c Crimmins MT, Bankaitis-Davis DM, Hollis WG Jr. J. Org. Chem 1988;53:652-657. d Holoboski MA, Koft E. J. Org. Chem 1992;57:965-969.

9. While it did not exclusively use asymmetric catalysis, Emil Koft had previous demonstrated that the spiroketal portion of Milbemycin $\beta_{3}$ could be prepared from an achiral starting material, see: ref $8 \mathrm{~d}$.

10. We prepared phosphine oxide 3 by a slightly modified variant of the Smith route, see Supporting Information and ref $7 \mathrm{~b}$.

11. Barrett had previously shown that the $C$-19 carboxylate could be installed by a Mitsunobu reaction, see: ref ${ }^{7 g}$. and Mitsunobu O. Synthesis 1981:1-28.

12. For examples of the asymmetric hydration of unsubstituted dienoates (e.g. 10 to 8), see: Hunter TJ, O'Doherty GA. Org. Lett 2001;3(7):1049-1052. [PubMed: 11277792]. Our study of the asymmetric hydration of substituted dienoates, will be published in due course.

13. a Rychnovsky SD, Kim J. J. Org. Chem 1994;59:2659-2660. b Trost B, Kazmaier U. J. Am. Chem. Soc 1992;114:7933-35.

14. Evans DA, Gauchet-Prunet JA. J. Org. Chem 1993;58:2446-2453.

15. Because most of the enantiomeric impurity in $\mathbf{7}$ is converted into the minor diastereomer $\boldsymbol{e n t} \mathbf{- 1 7 b}$ during the asymmetric dihydroxylation $(7$ to $17 \mathbf{a} / \mathbf{b})$, the major diastereomer diol $17 \mathbf{a}$ was isolated in essentially enantiomeric pure form. Consequently, the minor diastereomer $\mathbf{1 7 b}$ must be formed with lower enantiopurity. For other examples of this enantioenriching phenomena, see: Ahmed, Md. M.; Berry, BP.; Hunter, TJ.; Tomcik, DJ.; O'Doherty, GA. Org. Lett 2005;7:745-748. [PubMed: 15704940]

16. The $\mathrm{CH}_{2} \mathrm{Cl}_{2}$ /hexane solvent mixture was critically important to insure high yields for the palladium catalyzed reduction. For instance, use of THF as solvent gave a 1:1 mixture of double bond regioisomers.

17. a Nelson SG, Bungard CJ, Wang K. J. Am. Chem. Soc 2003;125:13000-13001. [PubMed: 14570453] b Nelson SG, Wang K. J. Am. Chem. Soc 2006;128:4232-4233. [PubMed: 16568990]

18. The synthetic material had a melting point range of $182-184{ }^{\circ} \mathrm{C}$ and an optical rotation of $+99(c=$ $0.25, \mathrm{MeOH})$ which is in good agreement with the literature value $\left(\mathrm{Mp}=181-183{ }^{\circ} \mathrm{C} ;[\alpha]_{\mathrm{D}}=+102\right.$ $(c=0.17, \mathrm{MeOH}))$. The actual value for the optical rotation of milbemycin $\beta_{3}$ has been a source of disagreement. For an interesting discussion of this issue along with its resolution, see: ref $7 \mathrm{~g}$.

Org Lett. Author manuscript; available in PMC 2009 January 9. 

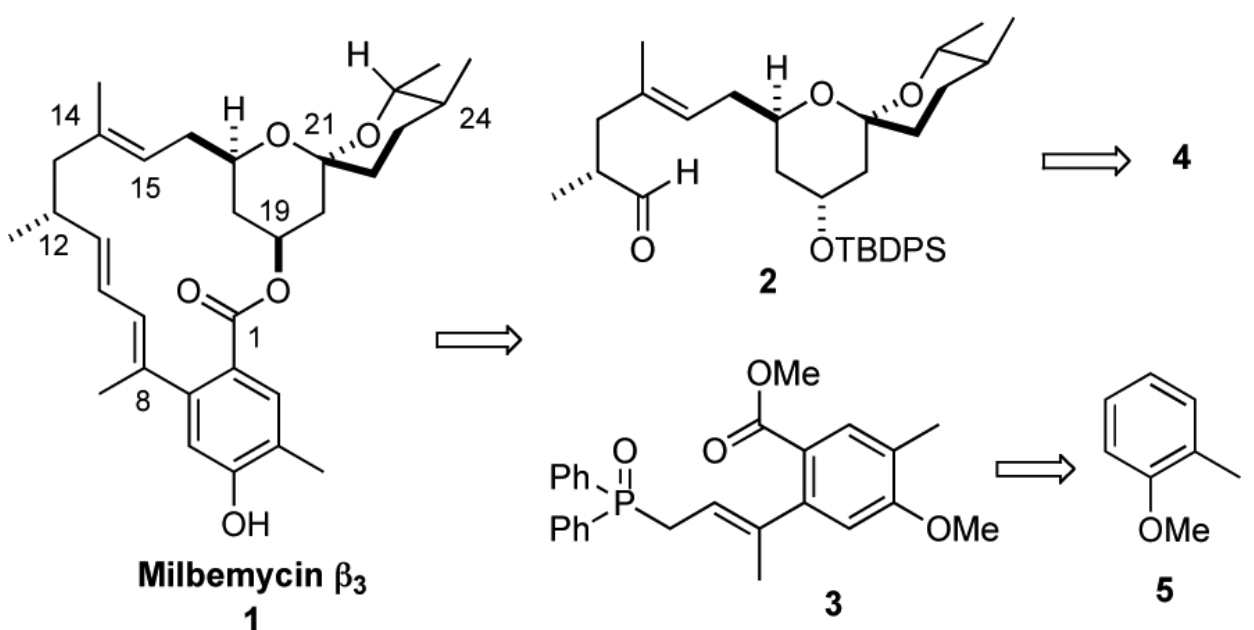

Scheme 1.

Milbemycin $\beta_{3}$ (1) and its Retrosynthesis. 
<smiles>C=CCCCOCCC1CC(CC(=O)C=CC(C)(C)[C@@H](C)O)OC(c2ccccc2)O1</smiles>

4

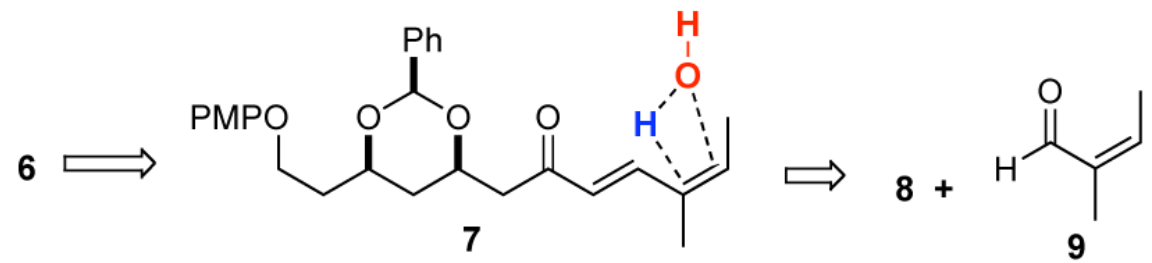

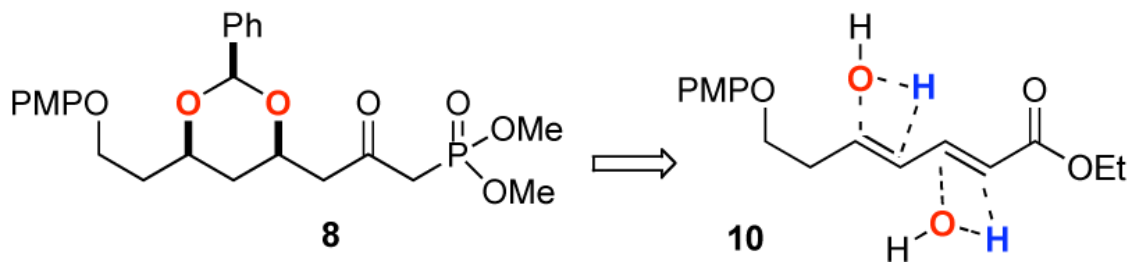

Scheme 2.

Retrosynthesis of Spiroketal 2. 

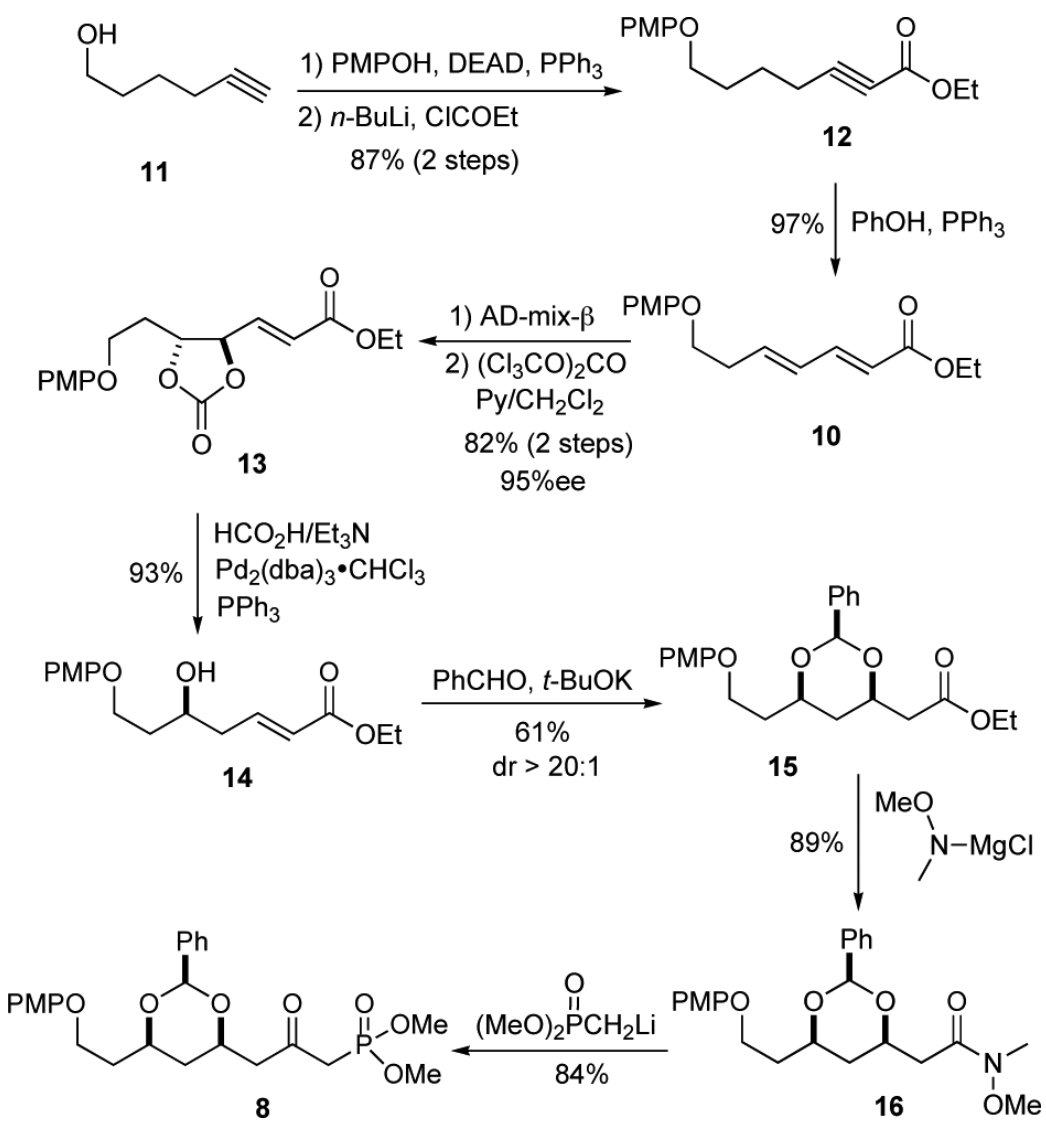

Scheme 3.

Synthesis and Bis-Hydration of Dienoate $\mathbf{1 0 .}$ 
<smiles>C/C=C(C)\C=C\C(=O)CC1CC(CCONC(=O)c2ccccc2)OC(c2ccccc2)O1</smiles>

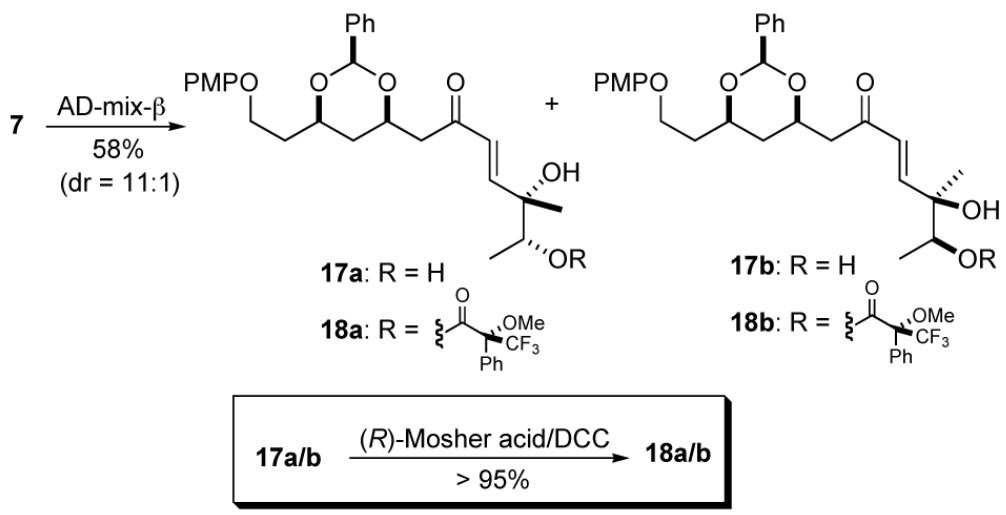

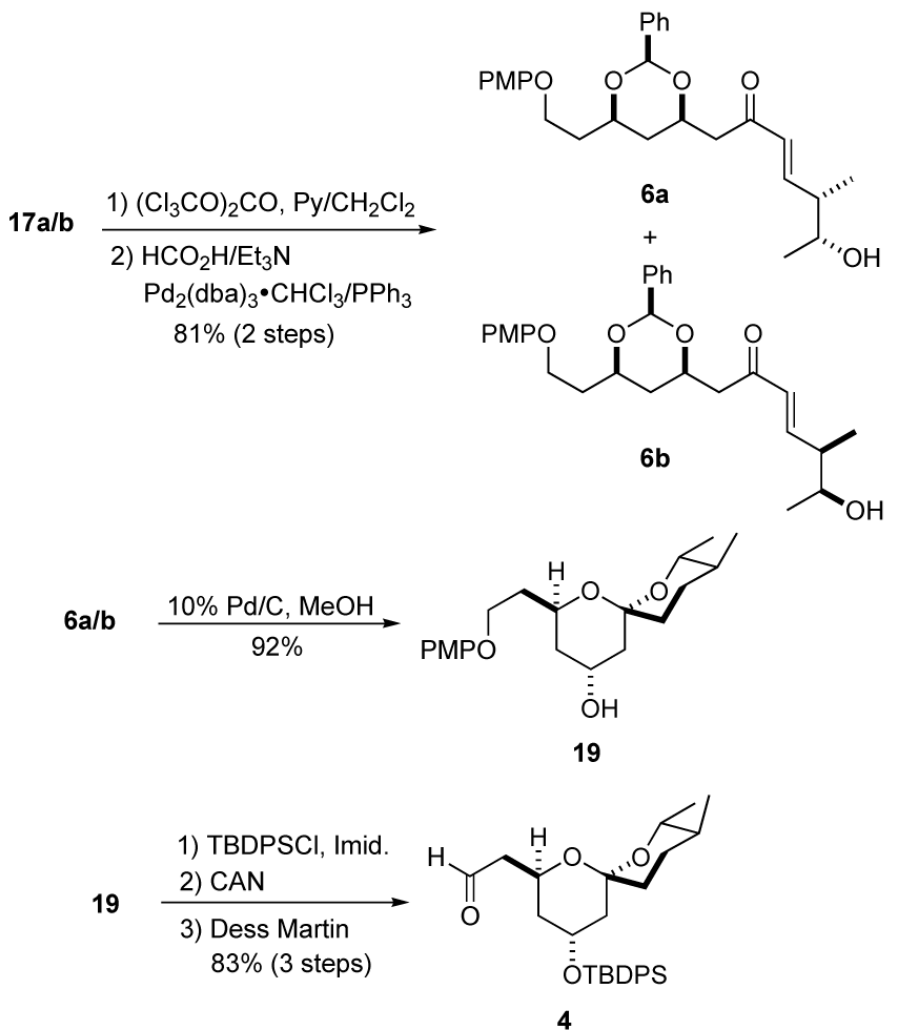

Scheme 4.

Synthesis of Spiroketal 4 via Dienone Hydration. 


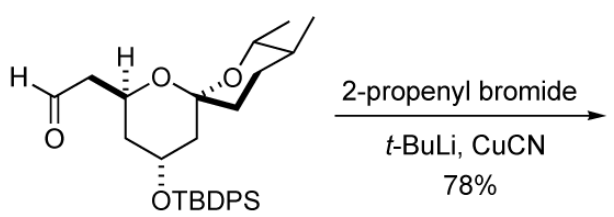

4

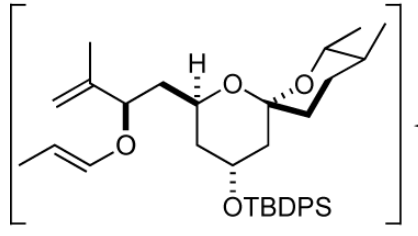

22

$83 \% \downarrow \mathrm{PPh}_{3}, 83^{\circ} \mathrm{C}$

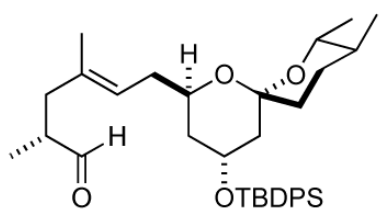

$2(\mathrm{dr}=10: 1)$ $\frac{1 \mathrm{~mol} \%\left[\left({ }^{\circ} \mathrm{C}_{8} \mathrm{H}_{14}\right)_{2} \mathrm{IrCl}\right]_{2}}{6 \mathrm{~mol} \% \mathrm{PCy}_{3}}$

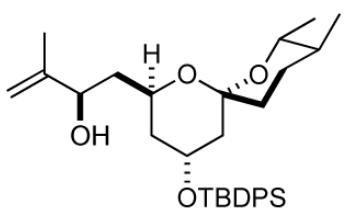

20 $99 \% \downarrow \frac{\text { allyl bromide }}{\mathrm{KH}}$

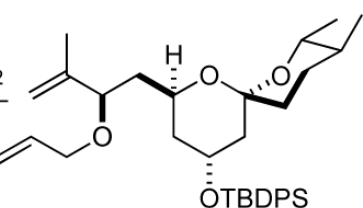

Scheme 5.

Synthesis of Aldehyde $\mathbf{2}$ via an ICR Reaction. 
<smiles>COC(=O)c1cc(C)c(OC)cc1/C(C)=C/CP(=O)(c1ccccc1)c1ccccc1</smiles><smiles>CCC=CC=C(C)c1cc(OC)c(C)cc1C(C)=CC=CC(=O)O[SnH3]</smiles>

\begin{tabular}{c|c}
$74 \%$ & $1) \mathrm{TBAF}$ \\
(2 steps) & 2) $\mathrm{LiOH}$
\end{tabular}

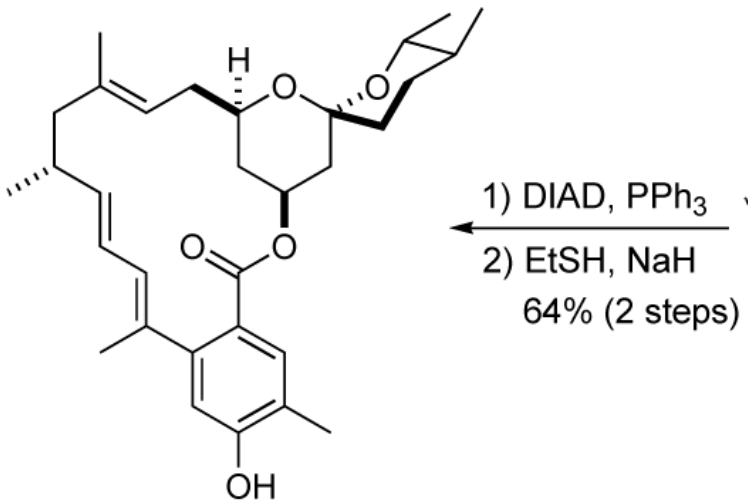

Milbemycin $\beta_{3}$

$2.3 \%$ (25 steps) from 11

Scheme 6.

Synthesis of Milbemycin $\beta_{3}(\mathbf{1})$ via a Macrolactonization. 